\title{
Estudios sonoros: una alternativa para la investigación artística en Costa Rica
}

Editora invitada: Dra. Susan Campos Fonseca

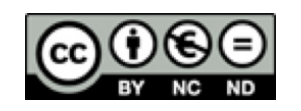

Esta obra está bajo una licencia Creative Commons Reconocimiento-No comercial-Sin Obra Derivada 
Nota editorial

\title{
Estudios sonoros: una alternativa para la investigación artística en Costa Rica
}

\author{
Dra. Susan Campos Fonseca ${ }^{1}$ \\ Universidad de Costa Rica \\ Costa Rica
}

Cuando iniciamos con el proyecto de este dossier, partimos de una serie de actividades que veníamos organizando desde 2013, en la Sede del Atlántico de la Universidad de Costa Rica. Les llamábamos "Encuentros sonoros", incluso en su momento les nombramos como "Debates sonoros" y, así, pueden encontrarnos en las múltiples formas que la sociedad digital conserva su memoria en internet. Organizábamos "Eventos sonoros" (no conciertos) y generábamos conversatorios y talleres que sobreviven hasta hoy, en la Escuela de Artes Musicales de la Sede Rodrigo Facio, bajo el mismo título de "Encuentros". Estos espacios, pensados desde una sede regional en mi pueblo natal, Turrialba, me enseñaron a estudiar la innovación, la invención y la experimentación desde la ruralidad, no solo desde los centros metropolitanos. Y desde este reconocimiento, escuchar lo que acontecía en Costa Rica y Centroamérica, propiciado por la creación en arte sonoro, electrónico y músicas experimentales, tejiendo redes internacionales. Un resultado de este trabajo es mi estudio "Noise, Sonic Experimentation, and Interior Coloniality in Costa Rica", capítulo No. 8 del libro Experimentalism in Practice: Music perspectives from Latin America, editado por Ana R. Alonso-Minutti, Eduardo Herrera y Alejandro L. Madrid.

Mi formación como musicóloga me obligaba a preguntar: ¿cómo se escriben los relatos sobre la creación experimental en Costa Rica?, ¿quiénes los escriben?, ¿desde dónde los escriben (perspectivas, objetivos, disciplinas, lugares, espacios, métodos, teorías, formatos, soportes)?, ¿qué influencia tienen estos relatos en la recepción de la creación experimental dentro y fuera del país? Guiada por estas preguntas, en un artículo que titulé "Ciberfeminismo y estudios sonoros" (Campos, 2016), señalé que la ciudad es un escenario donde "lo sonoro" y "lo musical", mediados por la tecnología, son material de represen tación de tipos de "modernidad". Esta idea no es ajena al patrimonio y no es la única de manifestaciones que consideramos innovadoras.

1 Docente en la Escuela de Música de la Universidad de Costa Rica y Directora de la Sede Interuniversitaria de Alajuela. Dra. en Música por la Universidad Autónoma de Madrid. Correo electrónico: susanconductor@gmail.com

ESCENA. Revista de las artes, 2018, Vol. 78, Núm. 1 (julio-diciembre), pp. 1-5. ISSN 2215-4906 
La portada de este número especial, un dibujo del artista costarricense José Pablo Ureña, profesor del proyecto Universidad de Costa Rica (UCR) en la Sede interuniversitaria de Alajuela, nos muestra un ejemplo, a saber: el Teatro Nacional y su representación de la nación moderna. La obsesión de la oligarquía cafetalera por representarse con los símbolos de la modernidad de su tiempo, en sus arquitecturas de poder, en sus rituales, sus símbolos, sus imaginarios culturales, sus máquinas, sus próceres y sus víctimas. Hoy la estatua del Beethoven introspectivo, coexiste con la cabeza decapitada de la escritora costarricense Yolanda Oreamuno. Estas acumulativas representaciones de modernidad, se yuxtaponen y se extienden en la ciudad.

Entonces, inspirada por el proyecto "Augmented Spaciality", desarrollado en ciudades como Estocolmo (2013), Valparaíso (2015), Málaga (2016) y Madrid (2017) por la Dra. María Andueza Olmedo, investigadora española que encabeza este dossier ${ }^{2}$, decidí que la convocatoria para recibir propuestas de artículos, debía centrar su atención en la creación sonora en el espacio social, no en el modelo "autor-obra" que ha dominado los relatos historiográficos sobre las prácticas sonoras y musicales en Costa Rica. Dicho recogimiento me motivó a proponer este dossier a la Dra. Patricia Fumero, directora del Instituto de Investigaciones en Arte-IIArte de la UCR, para ser incluido en ESCENA. Revista de las artes. Consideré que el espacio social debía ser la prioridad y junto al equipo editorial de la revista nos preguntamos ¿en qué medida quienes escribían pensaban ese espacio?, tomando en consideración lo tecnológico.

Consecuentemente, mi deseo es que este volumen sea un "encuentro sonoro". No puedo afirmar que las personas incluidas en este monográfico son todas especialistas en Estudios sonoros. Los Estudios sonoros (Sound Studies) serán entendidos aquí en relación a la gestión, comunicación, investigación e innovación en el entorno tecnológico ${ }^{3}$. Este es un campo de estudio interdisciplinar que considera: "the material production and consumption of music, sound, noise and silence, and how these have changed throughout history and within different societies, but does this from a much broader perspective than standard disciplines [la producción material y el consumo de música, sonido, ruido y silencio, y cómo estos han cambiado a lo largo de la historia y dentro de diferentes sociedades, pero lo hace desde una perspectiva mucho más amplia que las disciplinas estándar] (Pinch \& Bijsterveld, Octubre,

2 Información disponible sobre el proyecto en http://augmented-spatiality.org/ y https://mariaandueza.org/category/augmented-spatiality/

3 Para las personas que estén interesadas en explorar esta área de estudios, recomiendo iniciar con The Sound Studies Reader editado por Jonathan Sterne (Routledge, 2012), y Estudios sonoros desde la región andina, de Mayra Estévez Trujillo (Centro Experimental Oído Salvaje, 2008).

ESCENA. Revista de las artes, 2018, Vol. 78, Núm. 1 (julio-diciembre), pp. 1-5. ISSN 2215-4906 
2004, p. 636). En esta definición, las "disciplinas estándar" remiten a la musicología histórica y a la etnomusicología, donde ciertas ortodoxías marcan ámbitos de estudios diferenciados entre lo eurocéntrico y sus otros, la música notada y la grabada, la oralidad y la escritura, por ejemplo. Un caso de estás disciplinas aplicadas a la educación, son los programas de los cursos de Historia de la música, donde lo que en realidad se enseña, es una historiografía de las técnicas de composición musical y sus autores (hombres fundamentalmente), fortaleciendo cánones y relatos occidentales racializados, patriarcales y eurocentristas.

Por esta razón, los textos que conforman este dossier abordan desde diferentes disciplinas y especialidades, un fenómeno, una comunidad, una acción, un proyecto, que está vinculado con la creación sonora en el espacio social. Estos estudios se preguntan: ¿cómo la tecnología construye realidad histórica, imaginarios corporales, culturales, sociales, económicos y políticos? Los tres primeros artículos, "La posibilidad de hacer: la creación sonora en el espacio social" de María Andueza Olmedo, "Contexto sonoro expandido en el pensamiento equinoccial contemporáneo" de Norberto Bayo, "Mujeres en la música experimental y colectivos feministas en estudios sonoros en Brasil" de Isabel Nogueira y Tania Mello Neiva, proponen modelos metodológicos y conceptuales, aplicados a casos vinculados con su investigación actual en Europa e Iberoamérica. A continuación, los estudios "Del Video-mapping a la representación digital: espacio y mediación" de Rodolfo Rojas-Rocha, "Mirar con ruido. She knows so many secrets" de Ivan Sanabria-Solano y "Concierto de Chira, para tiorba y orquesta de guitarras. Una propuesta musical para sanar el olvido crónico" de Mario Solera, proponen la aplicación de modelos afines en el contexto de la investigación artística desarrollada en Costa Rica, desde los estudios visuales y la composición musical. Estos trabajos de corte científico-académico, se tejen con las reflexiones de Alejandro Sánchez Núñez en "Activismos: creación sonora y agricultura comunitaria" y Randall Zúñiga en "Audiotopía: rutas para una expedición sonora", donde los autores comparten procesos abiertos en sus proyectos políticos, artísticos, discográficos y radiofónicos.

La lectura de este bordado, propone una reflexión acerca de ¿qué investigación en estudios sonoros podemos desarrollar en Costa Rica? Este dossier pretende ser, ojalá, un detonante, un llamado a no centrar los estudios sobre lo sonoro y lo musical únicamente en figuras de compositores(as) y sus obras, en pos de relatos identitarios de diversa índole. Nuestro propósito es aunar esfuerzos para fortalecer una investigación artística desde los estudios sonoros, capaz de abrir nuevas y diversas vías de trabajo multi-, inter- y transdisciplinar que, a su vez, exploren las historias contingentes que cohabitan nuestro país y la región centroamericana. 
Costa Rica no cuenta todavía con la especialidad en musicología o etnomusicología en la educación universitaria, aunque algunas docentes e investigadoras poseemos títulos de posgrado en estas áreas. No obstante, la investigación musical ha ido de la mano de la Educación, la Historiografía y las Ciencias sociales, desde las primeras exploraciones etnográficas empíricas que compositores del Gran Área Metropolitana, emprendieron hacia las periferias del país, con "la misión" de crear "la música nacional". Corría la década de 1920 y las consecuencias de ese proyecto las encontramos hoy en las políticas culturales, económicas y sociales del país. Los estudios de corte historiográfico de la MSc. María Clara Vargas Cullell, junto a la investigación sobre etnografía institucional y educación musical decolonial del Dr. Guillermo Rosabal Coto, han evidenciado la importancia de prestar atención a estas consecuencias (Campos Fonseca, 2016). Este dossier se abre entonces a la pregunta de ¿qué investigación artística podemos desarrollar? si pensamos no desde "La Música" (en mayúscula), como una disciplina de las Artes, sino, como una manifestación de lo sonoro de lo social-cultural, donde lo musical es solo una parte, donde la partitura es solo una huella, una tecnología, un documento antropológico de universos sonoros complejos, que nos permiten explorar las intrincadas redes de la auralidad.

\section{Referencias}

Campos Fonseca, S. (2016). La cultura de la investigación y lo sonoro de lo social-cultural en Costa Rica: una aproximación. Yael Bitrán Goren y Cynthia Rodriguez Leija (coords.), Perspectivas y desafíos de la investigación musical en Iberoamérica. Memorias del Coloquio Iberoamericano sobre investigación musical IBERMUSICAS 2015 (pp. 107-118). Ciudad de México: CENIDIM.

Campos Fonseca, S. (enero-abril 2016). Ciberfeminismo y estudios sonoros. INTERdisciplinaria. Revista del Centro de Investigaciones Interdisciplinarias en Ciencias y Humanidades, 4(8), 141-162.

Campos Fonseca, S. (2018). Noise, Sonic Experimentation, and Interior Coloniality in Costa Rica. Ana R. Alonso-Minutti, Eduardo Herrera y Alejandro L. Madrid (eds.), Experimentalisms in Practice: Music perspectives from Latin America (pp. 161-186). Estados Unidos de América: Oxford University Press.

Pinch, T. \& Bijsterveld, K. (octubre, 2004). Sound Studies: new Technologies and Music. Social Studies of Science, 34(5), 635-648. DOI: 10.1177/0306312704047615

ESCENA. Revista de las artes, 2018, Vol. 78, Núm. 1 (julio-diciembre), pp. 1-5. ISSN 2215-4906 